\title{
"Successful Treatment of Acute Liver Failure due to Yellow Phosphorus Ingestion in a Rural, Low Resource Setting"
}

\author{
Bassem W Ghali*1,2, Timothy S Laux ${ }^{1,2}$, Gajanan B Phutke ${ }^{1}$, Reshma D Souza ${ }^{1}$ and Priyank Jain ${ }^{1,3}$ \\ ${ }^{1} J a n$ Swasthya Sahyog, Ganiyari, Chhattisgarh, India
}

${ }^{2}$ Health Equity Action Leadership (HEAL) Initiative, University of California San Francisco, San Francisco, California, USA

${ }^{3}$ Cambridge Health Alliance, Cambridge, Massachusetts, USA

Received: February 21, 2018; Published: May 15, 2018

*Corresponding author: Bassem W Ghali, Department of Hospital Medicine, 533 Parnassus Ave, Box 0131, U149, San Francisco, CA 94143, Secretar

Abstract

We present the case of a teenage girl who presented with hyperacute fulminant hepatic failure after ingesting a potentially lethal dose of yellow phosphorous rat poison and survived. We review the literature and describe the clinical course of yellow phosphorus poisoning, and focus on interventions appropriate to lower resource settings N-Acetylcysteine (NAC) and good supportive care.

Abbreviations: NAC: N-Acetylcysteine; FFP: Fresh Frozen Plasma; INR: International Normalized Ratio; MELD: Model For End-Stage Liver Disease; ASLD: American Association for the Study of Liver Diseases

\section{Key Message}

I. Yellow phosphorus ingestion and poisoning progresses in 3 stages: asymptomatic or GI side effects in first 24 hours, followed by asymptomatic 24-72 hours, followed by the delayed presentation of fulminant liver failure at 72 hours with high mortality. Avoid the false reassurances of the asymptomatic phase.

II. Poison removal followed by close clinical monitoring and good supportive care for liver failure remain the mainstays of therapy. Despite minimal evidence of clear benefit, we believe $\mathrm{N}$-Acetylcysteine(NAC) should be administered given its high safety profile and low cost. Further studies of NAC's efficacy in this and similar cases should be performed.

III. The National Poisons Information Centre toxicology hotline is sponsored by All India Institute Of Medical Sciences, New Delhi. You can call 24 hours a day, 7 days a week

i. http://www.aiims.edu/en/departments-and-centers/ central-facilities.html?id=167

ii. Telephone number: 26589391, 26593677. Toll Free Number: - 1800116 117;

\section{Case Presentation}

The patient is an 18 year old lady who presented to our facility with nausea soon after ingesting 5 grams of rat poison (brand name "Ratol") after a family argument. At presentation, the patient's vital signs and physical exam were normal and basic chemistries including liver and kidney function tests were within normal limits. The admitting physician contacted Ratol's manufacturer (Ultima Search, Vapi, Gujarat, ultimasearch.com, (022) 28722711) who reported the product as "red phosphorus". The National Poisons Information Centre toxicology hotline available through the All India Institute of Medical Sciences [1] reported that red phosphorus is not systemically absorbed and non toxic $[1,2]$. However, Ratol is yellow orange in color and raised our concern for presence of yellow phosphorus. So, we instructed the patient to return for daily testing over the next week. No gastric lavage or decontamination was done.

Two days after ingestion, the patient developed clinical and laboratory evidence of acute liver failure (Table 1) and we started her on an infusion of intravenous $\mathrm{N}$-acetylcysteine (NAC): 6 grams (150 mg/kg) loading dose over 1 hour, then $8 \mathrm{~g}$ over the next 4 
hours $(50 \mathrm{mg} / \mathrm{kg} / \mathrm{hr}$ ) and then $4 \mathrm{~g} / \mathrm{hr}(100 \mathrm{mg} / \mathrm{kg} / \mathrm{hr}$ ) for 15 hours; so a total of $74 \mathrm{~g}$ of NAC was administered over 21 hours. She had evidence of coagulopathy and we gave her $5 \mathrm{mg}$ of Vitamin K intramuscularly for 3 days and fresh frozen plasma (FFP) twice a day until her INR was $<2$. A total of 13 units of FFP were transfused. She had no significant bleeding. She developed evidence of bone marrow toxicity with leukopenia and thrombocytopenia. Six days after ingestion, she developed encephalopathy initially a subtle grade 1 , but she did progress to grade 3 briefly. Given her increasing encephalopathy and to ensure adequate enteral access we placed a nasogastric to deliver medications and low protein tube feeds. We treated her with lactulose $20 \mathrm{~g}$ three times daily via the nasogastric tube, bowel washouts with rectal saline enemas, ceftriaxone $1 \mathrm{~g}$ IV

Table 1: Laboratory investigations from the case. twice daily to reduce her gut flora and for infection prophylaxis . She had no clinical evidence of increased intracranial pressure such as papilledema and head CT scan was not performed. We also started her on pantoprazole for stress ulcer prophylaxis.

With aforementioned supportive care the patient's mental status and laboratory data began to improve by hospital day 6 (Table 1). She was seen by a psychologist who judged her actions impulsive and not suicidal. She was discharged to home on hospital day 9. Prior to discharge, she did provide written consent to document and disseminate her case. On follow-up visits one week and two weeks after discharge, the patient's laboratory data had normalized except for residual minor elevations in transaminases (Table 1) and she remained symptom free.

\begin{tabular}{|c|c|c|c|c|c|c|c|}
\hline & ED visit Jul 26 & $\begin{array}{c}\text { Admission (HD } \\
\text { 0- Jul 28) }\end{array}$ & HD 3, Jul 31 & HD 6, Aug 3 & $\begin{array}{c}\text { Discharge (HD } \\
\text { 9, Aug 6) }\end{array}$ & $\begin{array}{l}\text { 1st Follow up } \\
\text { (Aug 12) }\end{array}$ & $\begin{array}{l}\text { 2nd Follow up } \\
\text { (Aug 22) }\end{array}$ \\
\hline $\operatorname{ALT}(\mathrm{u} / \mathrm{mL})$ & 6 & 338 & 510 & 296 & 182 & 93 & 99 \\
\hline $\operatorname{AST}(\mathrm{u} / \mathrm{mL})$ & 22 & 829 & 1210 & 210 & 175 & 130 & 82 \\
\hline $\mathrm{T}$ bili $(\mathrm{mg} / \mathrm{dL})$ & 0.6 & $2.3(\mathrm{~d} 1.3)$ & $2.3(\mathrm{~d} 1.1)$ & $6.6(3.1)$ & $5(\mathrm{~d} 4.8)$ & & 1.5 \\
\hline Alk Phos (U/mL) & 145 & & & & & & \\
\hline Albumin $(\mathrm{g} / \mathrm{dL})$ & 4 & & & & & & \\
\hline INR (nd) & 1 & 2 & 4.1 & 1.3 & 0.9 & 1 & 0.9 \\
\hline $\mathrm{Cr}(\mathrm{mg} / \mathrm{dL})$ & (next day 0.6 ) & 0.7 & 0.6 & 0.6 & 0.5 & 0.6 & 0.5 \\
\hline $\mathrm{Na}(\mathrm{mmol} / \mathrm{L})$ & 132 & & 130 & 124 & 124 & 124 & 137 \\
\hline WBC (x10E9/L) & & & 2 & 6.1 & 11.7 & 5 & 4.7 \\
\hline $\mathrm{Hgb}(\mathrm{g} / \mathrm{dL})$ & 11.9 & & 11.3 & 10 & 10.2 & 11.5 & 10.2 \\
\hline Platelet (x10E9/L) & & & 43 & 49 & 58 & & 234 \\
\hline
\end{tabular}

Abbreviations: INR: International Normalized Ratio; Na: sodium; Cr: Creatnine; WBC: White Blood Cell count; Hgb: Hemoglobin, T bili: Total Bilirubin; D bili: Direct Bilirubin

\section{Discussion}

The manufacturer's hotline was mistaken. Ratol is 3\% yellow phosphorous (also known as white phosphorous), a far more toxic substance than red phosphorous $[3,4]$. Yellow phosphorus is categorized as a highly lethal rodenticide (chemicals where the lethal ingested dose, LD50, is less than $50 \mathrm{mg} / \mathrm{kg}[5,6]$ as ingested doses greater than $1 \mathrm{mg} / \mathrm{kg}$ are often fatal $[3,7]$. The patient ingested approximately $5 \mathrm{~g}$ of $3 \%$ phosphorus, or approximately 3 $\mathrm{mg} / \mathrm{kg}$.

\section{Epidemiology}

There are scarce epidemiological data regarding ingestion of yellow phosphorous in the subcontinent. Case series of general poisonings from Nepal [8], rodenticide poisonings from Mysore, India [6] and Rajasthan, India [9-12] all show a predominance of young adults between ages 15 to 40 years old. The Nepalese study highlighted the greatest burden among homemakers, laborers and farmers [13]. Extrapolating from our experience with organophosphate poisonings and as illustrated in this case, we surmise these ingestions are impulsive acts in an environment where highly toxic substances are cheap and readily available. This supposition is supported by previously published data from Sri Lanka, Karnataka and Rajasthan; in Karnataka, fully 94\% were impulsive acts of self harm $[6,9,10]$.

\section{Natural History, Treatment and Prognostic Factors}

The time course of a brief asymptomatic period followed by acute liver failure at 72 hours fits other clinical reports of yellow phosphorus ingestions $[3,6]$. We surmise that patients with yellow phosphorus poisoning should be observed closely for at least 3 days, given the 72 hour asymptomatic latent period. Other authors suggest a week [14]. Other toxic manifestations include central nervous system effects (restlessness, irritability, drowsiness, lethargy, stupor, or coma) $[11,12]$, acute tubular necrosis, bone marrow toxicity [13], arrhythmias and hemodynamic instability $[3,4]$. Clinical manifestations and outcome vary in different reports. In one case series, $87 \%$ had some hepatic derangement and $27 \%$ developed fulminant hepatic failure and died [7]. Similarly, mortality in a second case series was $28 \%$ [5]. Another series found a range of $23-73 \%$ mortality depending on clinical manifestations, with early central nervous system manifestations portending poorer prognosis [12]. MELD score has been described as a prognostic indicator in rodenticide poisoning (including yellow phosphorous): average MELD for those who died was 40.5 as compared to 11.7 for survivors [5]. The patient's highest MELD score was 32 (Creatinine 0.6, Total Bilirubin 6.6, INR 4.1).

No antidote to phosphorus poisoning has been described in the medical literature $[3,11,12]$. Treatment involves early decontami- 
nation followed by monitoring of liver function and supportive care [2-4]. Some recommend gastric lavage with 1:5000 potassium permanganate followed by activated charcoal and mineral oil cathartic $[12,13]$. Clinical studies in rodenticide poisoning have conflicting evidence about use of N-Acetylcysteine (NAC) and adjunctive therapies. One case series showed no benefit [7]; in contrast, Nalabothu et al. suggest that early use of NAC improves outcomes for all rodenticide poisonings with liver failure. In that study, survival rates varied based on timing of NAC administration after rodenticide ingestion: 76\% survival rates if NAC was administered on Day 1, 40\% survival if administered on Day 2 and 23\% survival if administered 3 or more days after ingestion [5] though this data is confounded by early gastric lavage for those presenting shortly after consumption. In light of NAC's safety profile and recent guidelines suggesting a role for NAC in non-acetaminophen based liver failure [14], we chose to administer this drug. Other adjuncts such as corticosteroids and exchange transfusion have been studied but have not shown clinical benefit [15].

In the Fernandez et al. [7] case series of acute liver failure secondary to phosphorus ingestion, the two causes of death were massive upper gastrointestinal bleeding and cerebral edema. In their series, 73\% had prolonged PT time and received FFP while only $40 \%$ of patients had signs of bleeding [7]. Current American Association for the Study of Liver Diseases (AASLD) guidelines for management of acute liver failure recommend at least one dose of vitamin K subcutaneously, reserving FFP and platelet transfusion for those with active bleeding or needing invasive procedures [11]. These same guidelines suggest proton pump inhibitors or $\mathrm{H} 2 \mathrm{re}$ ceptor antagonists for ulcer prophylaxis [14]. The patient received 13 units of fresh frozen plasma, intramuscular vitamin $\mathrm{K}$ and pantoprazole during her hospital stay. She did not develop clinically significant bleeding. Due to India's strict legislation regarding blood banking, this had to be procured by the patient's brother from a hospital in a nearby city. Our inability to maintain a blood bank has serious implications for the care of critically ill patients like our patient [16]. Few patients have families with the time or financial wherewithal to travel to and from the local city this frequently.

Her confusion may have been related to the yellow phosphorous (which itself can cause altered sensorium) [3] or to hepatic encephalopathy from the liver failure. AASLD guidelines suggest that lactulose may be helpful to reduce ammonia burden [14]. Lactulose is cheap, easily available and has minimal side effects, so we administered it by nasogastric tube. We supplemented this with rectally administered saline bowel washouts. Bowel washouts, sometimes acidified with $1 \%$ acetic acid, are used in pediatric acute liver failure [17]. Acidified bowel washouts, particularly lactulose are thought to work by 1) removing stool (and the source of ammonia by virtue of colonic bacteria), 2) by acidifying the colon, and perhaps inhibiting growth of ammonia producing organisms and 3) by trapping ammonium in the colon which is then discarded in the feces and not absorbed[18,19]. Use of antibiotics as a gut decontaminant or as prophylaxis against infection in acute liver failure remains controversial in the current guidelines [14]. We are limited in our ability to closely surveil for infection and we decided to prophylactically use ceftriaxone.

\section{Conclusion}

Cheap poisons affect the most vulnerable in our population - children and adolescents and poor agricultural workers [5,6]. We agree with several authors in banning yellow phosphorous in rodenticides and fireworks in its currently packaged, concentrated, lethal form [2,3]. We offer clinical pearls in diagnosis and management in a case of liver failure from yellow phosphorus. Excellent supportive care is one important aspect to reducing morbidity and mortality from these ingestions. We are currently drafting an article that proposes a broader public health framework that addresses decreasing the morbidity mortality from these highly lethal ingestions: including safer packaging improved, storage practices, alternative load control practices, more stringent post market surveillance expanded use of toxicology hotlines for research and consultation.

\section{Acknowledgement}

Dr. Yogesh Jain and Dr. Raman Kataria for their thoughts on this manuscript, their mentorship and their passion for serving the poor which has inspired us. Acknowledgement of financial support: To the best of our knowledge, we authors have no conflicts of interest to disclose. The time needed to create the report was funded by own time and our salaries from our respective institutions.

\section{References}

1. PHOSPHORUS, ELEMENTAL (2017) National Library of Medicine HSDB Database [Internet].

2. Mauskar A, Mehta K, Nagotkar L, Shanbag P (2011) Acute hepatic failure due to yellow phosphorus ingestion. Indian J Pharmacol 43(3): 355-356.

3. Mohideen SK, Kumar KS (2015) Should ratol paste be banned? Indian J Crit Care Med 19(2): 128-129.

4. Lakshmi CP, Goel A, Basu D (2014) Cholestatic presentation of yellow phosphorus poisoning. J Pharmacol Pharmacother 5(1): 67-69.

5. Nalabothu M, Monigari N, Acharya R (2015) Clinical Profile and Outcomes of Rodenticide Poisoning in Tertiary Care Hospital. International Journal of Scientific and Research Publications 5(8): 1-12.

6. Suneetha DK, Inbanathan J, Kannoth S, Reshma PK, Shashank MS (2016) Profile of Rat Killer Poisoning Cases in a Tertiary Care Hospital at Mysore.

7. Fernandez OU, Canizares LL (1995) Acute hepatotoxicity from ingestion of yellow phosphorus-containing fireworks. J Clin Gastroenterol 21(2): 139-142.

8. Agrawaal KK, Karki P (2014) Clinico-epidemiological Study on Pesticide Poisoning in a Tertiary Care Hospital in Eastern Nepal. JNMA J Nepal Med Assoc 52(196): 972-976.

9. Pahadia M, Registrar S, Bhushan B, Professor A, Saluja M, et al. (2013) Impact on Morbidity \& Mortality by Rodenticidal Poisoning. Indian Medical Gazette.

10. Roberts DM, Karunarathna A, Buckley NA, Manuweera G, Sheriff MHR, et al. (2003) Influence of pesticide regulation on acute poisoning deaths in Sri Lanka. Bull World Health Organ 81(11): 789-798.

11. Saoji AA, Lavekar AS, Salkar HR, Pawde GB, Tripathi SS (2014) A Case on Suicidal Poisoning Associated with Ratol and a Perspective on Yellow Phosphorus Poisoning. Int J Re Sci\& Techi 10: 223-225.

12. McCarron MM, Gaddis GP, Trotter AT (1981) Acute yellow phosphorus poisoning from pesticide pastes. Clin Toxicol 18(6): 693-711.

13. Tafur AJ, Zapatier JA, Idrovo LA, Oliveros JW, Garces JC (2004) Bone marrow toxicity after yellow phosphorus ingestion. Emerg Med J 21(2): $259-260$. 
14. Lee WM, Larson AM, Stravitz RT (2011) AASLD position paper: the management of acute liver failure: update 2011. Hepatology 55: 965967.

15. Marin GA, Montoya CA, Sierra JL, Senior JR (1971) Evaluation of corticosteroid and exchange-transfusion treatment of acute yellowphosphorus intoxication. N Engl J Med 284(3): 125-128.

16. Jain Y, Kataria R (2016) Rural blood availability: regulations must meet ethics. Indian J Med Ethics 1(4): 237-242.

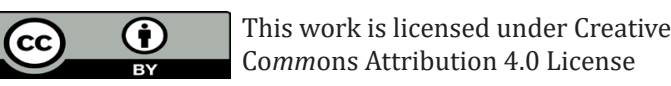

Submission Link: https://biomedres.us/submit-manuscript.php
17. Bhatia V, Lodha R (2010) Intensive care management of children with acute liver failure. Indian J Pediatr 77(11): 1288-1295.

18. Uribe M, Campollo O, Vargas F, Ravelli GP, Mundo F, Zapata L, et al. (1987) Acidifying enemas (lactitol and lactose) vs. nonacidifying enemas (tap water) to treat acute portal-systemic encephalopathy: a double-blind, randomized clinical trial. Hepatology 7(4): 639-643.

19. Insecticide Rules (19710 (GSR 1650, DT. 9-10-1971) Central Insecticides Board and Registration Committee.

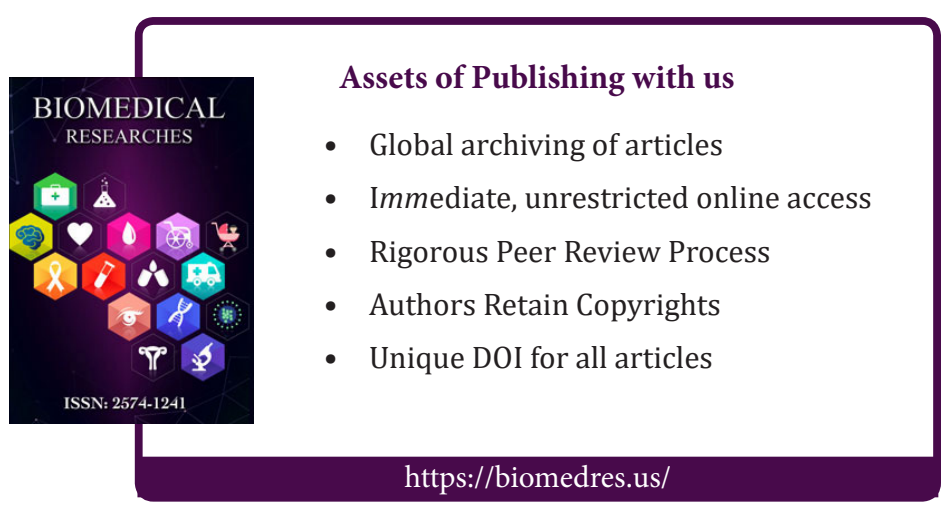

